\title{
Pharmacokinetics of a Prototype Formulation of Sublingual Testosterone and a Buspirone Tablet, Versus an Advanced Combination Tablet of Testosterone and Buspirone in Healthy Premenopausal Women
}

\author{
Kim van Rooij • Leo de Leede • Henderik W. Frijlink • \\ Jos Bloemers · Saskia Poels • Hans Koppeschaar • \\ Berend Olivier • Adriaan Tuiten \\ Published online: 22 May 2014 \\ (C) The Author(s) 2014. This article is published with open access at Springerlink.com
}

\begin{abstract}
The study aimed to compare the kinetics of two novel combination drug products for Female Sexual Interest/Arousal Disorder (FSIAD). Thirteen women received testosterone via the sublingual route followed 2.5 hours later by a buspirone tablet, versus a single combination tablet swallowed at once. The first clinical prototype consisted of a sublingual solution containing testosterone $(0.5 \mathrm{mg})$ complexed with cyclodextrin and a tablet containing $10 \mathrm{mg}$ buspirone, in a gelatin capsule to ensure blinding during the clinical studies. The innovative fixed-combination tablet consists of an inner-core component of $10 \mathrm{mg}$ buspirone coated with a polymeric time-
\end{abstract}

K. van Rooij ( $\square)$ · J. Bloemers · S. Poels · H. Koppeschaar . A. Tuiten

Emotional Brain B.V., Louis Armstrongweg 78,

1311 RL Almere, The Netherlands

e-mail: k.vanrooij@emotionalbrain.nl

K. van Rooij · J. Bloemers · S. Poels · B. Olivier

Utrecht Institute for Pharmaceutical Sciences and Rudolf

Magnus Institute of Neuroscience, Utrecht University, Utrecht,

The Netherlands

L. de Leede

Exelion Bio-Pharmaceutical Consultancy B.V., Waddinxveen, The Netherlands

H. W. Frijlink

Department of Pharmaceutical Technology and Biopharmacy, University of Groningen, Groningen, The Netherlands

B. Olivier

Department of Psychiatry, Yale University School of Medicine, New Haven, CT, USA

A. Tuiten

Department of Psychopharmacology, Utrecht University,

Utrecht, The Netherlands delay coating and an outer polymeric coating containing testosterone with hydroxypropyl-beta cyclodextrin. We observed an immediate testosterone pulse absorption from both formulations. We also demonstrated that there was adequate absorption of buspirone ( $>80 \%$ relative to the conventional tablet) and a time delay in release of buspirone of 3.3 hours, close to the 3.0 hours of the reference formulation that showed clinical efficacy in early proof-ofprinciple studies. The newly developed combination tablet fulfils its design criteria and is a convenient tablet for further clinical studies in FSIAD.

\section{Introduction}

Human sexual behavior is extensively studied in biology, medicine and psychology, but so far there is limited success in the development of drugs for the treatment of sexual dysfunction in women. Low sexual desire, with or without sexual arousal problems, is the most common sex-related complaint reported by women [1-3]. As a result, many women suffer from sexual dissatisfaction, which often negatively interferes with psychological well-being [4]. This has been classified as a clinical condition, referred to as Hypoactive Sexual Desire Disorder (HSDD) [5] or, as recently renamed, Female Sexual Interest/Arousal Disorder (FSIAD) [6]. We have developed two new promising potential treatments for HSDD/FSIAD which are based on the premise that this disorder can have (at least) two different causes [7, 8].

For women who have a low sensitivity to sexual cues, Lybrido is indicated. Lybrido is the combination of sublingual testosterone and a phosphodiesterase type 5 (PDE-5) inhibitor, which is absorbed from the gastro-intestinal tract. Sublingual testosterone $(0.5 \mathrm{mg})$ produces an increase in 
sexual motivation and desire in sexually functional women, about 4 hours after its peak plasma levels (time to maximum concentration $\left[T_{\max }\right]=15 \mathrm{~min}$ ) [9]. The testosterone and the PDE-5 inhibitor are released in such a timeframe that the peak plasma concentration of the PDE-5 inhibitor coincides with the 4-hour delay in behavioral effects of the testosterone. In women with low sensitivity to sexual cues, this combination showed superiority over placebo in increasing sexual satisfaction $[7,10]$. For women who have a dysfunctional activation of sexual inhibitory mechanisms during sexual stimulation, Lybridos is developed. Lybridos is the combination of sublingual testosterone and a $5-\mathrm{HT}_{1 \mathrm{~A}}$ receptor agonist (buspirone), released in such a timeframe that the pharmacological effects of the $5-\mathrm{HT}_{1 \mathrm{~A}}$ receptor agonist coincide with the behavioral window induced by the testosterone administration [8]. This combination in women with dysfunctional activation of sexual inhibitory mechanisms increased sexual satisfaction compared with placebo [8]. In previous clinical trials, the two components (sublingual testosterone in combination with a PDE-5 inhibitor or $5-\mathrm{HT}_{1 \mathrm{~A}}$ receptor agonist) were administered separately; however, these components have been developed into one single combination tablet in recent phase IIb trials.

Both products are intended for use on a 'per need' (i.e., not continuous or chronic) basis before anticipated sexual activity. Studies performed by various researchers have clearly indicated a time lag of about 3-4 hours in the pharmacodynamics effect of sublingual testosterone on genital arousal in women and other cognitive and affective functions [9, 11-23]. Therefore, either the PDE5 inhibitor (Lybrido) or (5-HT1a) receptor agonist (Lybridos) component needs to be administered approximately 2-3 hours after administering the testosterone. In the above-mentioned clinical studies, this was obtained by administering the testosterone sublingually as a solution, followed 2.5 hours later by a PDE-5 inhibitor (sildenafil) or a $5-\mathrm{HT}_{1 \mathrm{~A}}$ receptor agonist (buspirone) as a tablet (to ensure blinding, the tablet was administered in a gelatin capsule), thus creating overlapping peaks in effect of testosterone and sildenafil or buspirone. Because this kind of administration is not suitable and rather cumbersome for daily use in practice, we developed a single oral combination tablet that will deliver testosterone sublingually and, approximately 2.5 hours later in the gastro-intestinal tract, the sildenafil or buspirone component, allowing women with FSIAD to take just one single tablet 3-6 hours before the anticipated sexual activity.

The objective of this study was to see if the pharmacokinetic profile of testosterone given sublingually followed 2.5 hours later by a tablet of buspirone (administered in a gelatin capsule) mimics the pharmacokinetic properties of the newly developed single combination tablet as described above. The results of the pharmacokinetic study of the combination of testosterone and sildenafil will be described separately.

At frequent time points, plasma samples were taken and the following pharmacokinetic parameters were determined: the time to maximum concentration $\left(T_{\max }\right)$, half-life $\left(T_{1 / 2}\right)$, maximum concentration $\left(C_{\max }\right)$, and area under the curve (AUC) for total testosterone, free testosterone, buspirone, and buspirone's main metabolite (1-(2-pyrimidinyl)-piperazine) for each formulation.

\section{Methods}

\subsection{Study Subjects}

Eligible women were aged between 18 and 35 years, premenopausal, and had a body mass index (BMI) between 18 and $30 \mathrm{~kg} / \mathrm{m}^{2}$. Exclusion criteria included an endocrine disease, neurological problems, a cardiovascular condition, hypertension, abnormal liver or renal function, and a history of a hormone-dependent malignancy. Women taking medications that interfere with the metabolism of sex steroids (e.g., oral contraceptives containing anti-androgens or (anti)androgenic progestogens), or who used serotonergic drugs or who had used testosterone therapy within 6 months before study entry were also excluded.

Women were recruited and enrolled from advertisements, and via a database of a contract research organization (QPS in the Netherlands). Recruitment started in June 2012 and the study was ended in November 2012. To determine eligibility, participants were screened approximately 4 weeks prior to study entry. In addition to an assessment of medical history, all subjects received a physical examination including a 12-lead electrocardiogram, standard biochemistry, serology, and hematological laboratory tests. Blood samples for determination of baseline levels of total testosterone, sex hormone-binding globulin (SHBG), albumin, thyroid-stimulating hormone (TSH), follicle-stimulating hormone (FSH) and estrogen were collected at the screening visit. A urine pregnancy test was applied to all women.

Thirteen healthy young women participated after providing written informed consent. This study was approved by the local medical ethics committee (Stichting BEBO, Assen, the Netherlands) and carried out in agreement with the International Conference on Harmonisation-Good Clinical Practice (ICH-GCP).

\subsection{Study Design}

This was a single-center, investigator-blind, randomized, cross-over controlled study investigating two different modes of administration of a combination of testosterone 
and buspirone. The first mode (F1) consisted of the administration of a sublingual solution containing testosterone $(0.5 \mathrm{mg})$ complexed with cyclodextrin, followed 2.5 hours later by an orally administered tablet containing $10 \mathrm{mg}$ buspirone hydrochloride in a gelatin capsule. The second mode of administration (F2) consisted of an innovative fixed-combination tablet with an inner-core component of $10 \mathrm{mg}$ buspirone hydrochloride coated with a polymeric ethylcellulose-based time-delay coating and an outer coating containing $0.5 \mathrm{mg}$ testosterone complexed with hydroxypropyl- $\beta$ cyclodextrin.

All 13 subjects received the investigational drug formulation in random order. Wash-out between treatments was at least 7 days. Subjects had serial blood samples drawn via an intravenous catheter. Pharmacokinetic parameters were monitored at baseline $(-10 \mathrm{~min})$ and (at $5,10,15,20,25,30,60,90,120,135,145,165,180,195$, 210, 225, 240, 270, 300, 330, 360, 390, 450, 570, 690, 810, 930, 1,590 $\mathrm{min}$ ) after dosing.

Measurement of total testosterone, free testosterone, and dihydrotestosterone were performed at $-10,5,10,15,20$, $25,30,60,90,120,145,180,240$ and 1,590 minutes after dosing; buspirone and metabolite 1-(2-pyrimidinyl)-piperazine at $-10,10,30,60,90,120,135,145,165,180,195$, 210, 225, 240, 270, 300, 330, 360, 390, 450, 570, 690, 810, 930, 1,590 minutes after dosing.

For each admission period, subjects were instructed to come to the study site on the evening prior to dose administration where vital signs were checked (including ECG) and urine drug test, pregnancy test, and alcohol breath analysis were performed. During the admission period, the subjects received low calorie meals on site and decaffeinated coffee and tea to minimize the influence on pharmacokinetic parameters. Drug, alcohol, and pregnancy tests were performed prior to experimental sessions.

\subsection{Medication and Dosing}

The combination tablet is a menthol-flavored white tablet of $9 \mathrm{~mm}$ in diameter for sublingual administration followed by oral administration. The quickly dissolving outer coating, applied by film coating the tablet, delivers cyclodextrin-complexed testosterone $(0.5 \mathrm{mg})$ sublingually, and the time-delayed-release core delivers buspirone $(10 \mathrm{mg})$ 2.5 hours later. The outer coating comprises testosterone, excipients, and a menthol flavor to guide the disappearance of the coating. The testosterone coating is designed to fully dissolve and to obtain a fast and complete absorption via the mucosal membranes under the tongue. The timedelayed-release core containing the buspirone has been designed on the basis of in-vitro release studies of US Pharmacopeia (USP) II and III, to release the buspirone in a pulsatile manner, approximately 2.5 hours after oral administration. This method of release is accomplished through the use of a polymer coating of ethylcellulose which allows for a slow permeation of water in a $\mathrm{pH}$ independent manner. At the predetermined time, the polymer coating ruptures at the edge of the tablet. The complete disintegrated core of the inner tablet is released immediately, after which there is no delay for the dissolution of the buspirone in the surrounding fluid.

The two formulations were administered by a trained research associate and controlled by a second research associate.

For the testosterone component of $\mathrm{F} 1$, a $1 \mathrm{mg} / \mathrm{mL}$ testosterone cyclodextrin complex solution was used; the solution was administered with a micropipette (e.g., Eppendorf) into the subject's mouth under the tongue, and the subjects were instructed to keep the solution sublingually for 60 seconds while moving the tongue slightly to optimize absorption. After 60 seconds the subject was instructed to swallow the solution. The buspirone component of F1 was administered orally, as an encapsulated tablet with a glass of water (approximately $200 \mathrm{~mL}$ ) 150 minutes later.

For F2, the subject was instructed to keep the tablet in the mouth sublingually for 90 seconds, while moving the tongue slightly to optimize absorption. The amount of time that the tablet was in the mouth was timed so that the tablet was swallowed at exactly the right time. After 90 seconds, the subject was instructed to swallow the tablet as a whole, without chewing or otherwise disrupting the dosage form. If necessary, the subject could take a glass of water to enable swallowing.

\subsection{Hormone Assays}

The assay used for the determination of total testosterone and dihydrotestosterone was High Performance Liquid Chromatography with Mass Spectrometric detection (HPLC-MS/MS) (API 4000, Applied Biosystems, MDS SCIEX). Free testosterone was determined in plasma through ultra-filtration followed by HPLC-MS/MS. The method was validated with a lower limit of quantification (LLOQ) of $1.00 \mathrm{pg} / \mathrm{mL}$ for free testosterone with an intraassay coefficient of variation $(\mathrm{CV})$ of $5.2 \%$ and an interassay $\mathrm{CV}$ of $12.6 \%$. The LLOQ for testosterone was $0.02 \mathrm{ng} / \mathrm{mL}$ with an intra-assay $\mathrm{CV}$ of $11.0 \%$ and an interassay $\mathrm{CV}$ of $12.8 \%$. The LLOQ for dihydrotestosterone was $0.02 \mathrm{ng} / \mathrm{mL}$ with an intra-assay $\mathrm{CV}$ of $23.6 \%$ and an inter-assay $\mathrm{CV}$ of $29.5 \%$. The HPLC-MS/MS assay is a reliable and sensitive method for the analysis of free testosterone and overcomes the known limitations of direct immunoassays in measurement of testosterone values in the lower range [24, 25]. 
2.5 Buspirone and 1-(2-Pyrimidinyl)-Piperazine Assay

The analytes buspirone and its major metabolite 1-(2pyrimidinyl)-piperazine were determined in plasma by HPLC-MS/MS. The method was validated with a LLOQ of $0.01 \mathrm{ng} / \mathrm{mL}$ for buspirone with an intra-assay $\mathrm{CV}$ of $12.9 \%$ and an inter-assay $\mathrm{CV}$ of $7.2 \%$. The LLOQ for 1-(2-pyrimidinyl)-piperazine was $0.20 \mathrm{ng} / \mathrm{mL}$ with an intra-assay $\mathrm{CV}$ of $9.4 \%$ and an inter-assay $\mathrm{CV}$ of $4.7 \%$.

\subsection{Statistical Analysis}

The pharmacokinetic parameters were analyzed using the Watson 7.2 Bioanalytical LIMS software (Thermo Electron Corporation, Philadelphia, USA).

Pharmacokinetic parameters including AUC, $C_{\max }, T_{\max }$ and $T_{1 / 2}$ were calculated based on actual and baseline corrected individual concentration-time curves. AUCs were estimated using the linear trapezoidal rule. $C_{\max }$ and $T_{\max }$ were taken from the measured values. $T_{1 / 2}$ was calculated from the unweighted linear regression of the log transformed data determined at the elimination phase of the pharmacokinetic profile of each subject.

The $\mathrm{AUC}_{0-1,590}$ was determined as the area under the concentration versus time curve from the first time point to the last time point with measurable drug concentration with a linear/log-linear trapezoidal model. The $\mathrm{AUC}_{0-\infty}$ was calculated from the $\mathrm{AUC}_{0-1,590}$ by the addition of a constant $(\mathrm{Cp} / \lambda \mathrm{z})$, where $\mathrm{Cp}$ is the last observed quantifiable concentration and $\lambda z$ is elimination rate constant. This was performed by dividing the $\mathrm{Cp}$ by $\lambda \mathrm{z}$ determined using linear regression of $\mathrm{Cp}$ versus time data (standard extrapolation technique). The elimination rate constant and the corresponding elimination half-life was estimated by log-linear least squares regression of the terminal part of the plasma concentration versus time curve. Absorption lag time (Tlag) is determined as the first time point with a measurable concentration in plasma.

The demographic baseline levels of total and free testosterone, dihydrotestosterone, SHBG, and albumin were calculated by taking the mean of F1 and F2. For the baseline corrected pharmacokinetic parameters, the raw data of each subject was taken as baseline. Dependent on distribution of normality, paired-samples $t$ tests were used for the difference between the F1 and F2 pharmacokinetic parameters for the subjects of whom F1 and F2 data was obtained $(n=12)$. For all analyses a (two-sided) $p$ value $<0.05$ was considered statistically significant. Statistical analyses were conducted with SPSS 19.0 (IBM SPSS Statistics for Windows, Version 19.0. Armonk, NY: IBM Corp).

\section{Results}

The baseline characteristics and hormone levels of the 13 study participants are outlined in Table 1. Because one subject discontinued after F1 dose, an additional subject was included into the study in order to have F1 and F2 data from 12 subjects. Therefore, 13 subjects were included in $\mathrm{F} 1$ and 12 subjects were included in F2. Table 1 shows the baseline demographics of the 13 study participants, all subjects were Caucasian and the mean age was 25.8 years. Baseline levels (measured at screening) of testosterone, SHBG, and albumin were all in the normal female range.

\subsection{Pharmacokinetic Results}

\subsubsection{Testosterone, Free Testosterone and Dihydrotestosterone}

Pharmacokinetic results of the two administrations show that from both products, testosterone was rapidly absorbed with a total testosterone $T_{\max }$ between 12 and 16 minutes (0.201-0.256 h) and a half-life between 36 and 44 minutes $(0.598-0.726 \mathrm{~h})$. Free testosterone reached the maximum concentration within $12-15$ minutes $(0.194-0.250 \mathrm{~h})$ with a half-life between 40 and $48 \mathrm{~min}(0.674-0.798 \mathrm{~h}) . C_{\max }$ is significantly higher for total $(p=0.003)$ and free testosterone ( $p=0.003$ ) after F2 administration compared with F1 dosing. Furthermore, it is observed that the average AUC with F2 dosing is significantly higher for free

Table 1 Baseline and clinical characteristics of the participants

\begin{tabular}{ll}
\hline Characteristic & Value $(n=13)$ \\
\hline Age (years) & $25.8 \pm 4.9$ \\
Race & 13 \\
$\quad$ Caucasian & $22.9 \pm 2.1$ \\
BMI $\left(\mathrm{kg} / \mathrm{m}^{2}\right)$ & \\
Contraceptive & 12 \\
Hormonal & 8 \\
$\quad$ Combined oral contraceptive pill & 3 \\
$\quad$ IUD (levonorgestrel) & 1 \\
$\quad$ Vaginal ring (progestin and estrogen) & 1 \\
Non-hormonal & $0.26 \pm 0.1$ \\
Total testosterone (ng/mL) & $92 \pm 80$ \\
SHBG (nmol/L) & $41.5 \pm 2.8$ \\
Albumin (g/L) &
\end{tabular}

Baseline levels of total testosterone, SHBG and albumin were measured at the screening visit

The values are mean $\pm \mathrm{SD}$. To convert total testosterone to nanomoles per liter, multiply by 3.467

$B M I$ body mass index, $I U D$ intrauterine device, $S H B G$ sex hormonebinding globulin 
Table 2 Pharmacokinetic parameters for total testosterone, free testosterone, and dihydrotestosterone after F1 and F2 administration

\begin{tabular}{lcllr}
\hline Dosing & $C_{\max }(\mathrm{ng} / \mathrm{mL})$ & $T_{\max }(\mathrm{h})$ & $\mathrm{AUC}_{(0-1,590)}(\mathrm{ng} * \mathrm{~h} / \mathrm{mL})$ & $T_{1 / 2}(\mathrm{~h})$ \\
\hline F1 total testosterone $(\mathrm{ng} / \mathrm{mL})$ & $5.65 \pm 2.35$ & $0.256 \pm 0.063$ & $6.41 \pm 2.23$ & $0.726 \pm 0.165$ \\
F2 total testosterone $(\mathrm{ng} / \mathrm{mL})$ & $7.84 \pm 3.69 *$ & $0.201 \pm 0.043$ & $8.10 \pm 2.49$ & $0.598 \pm 0.080$ \\
F1 free testosterone $(\mathrm{pg} / \mathrm{mL})$ & $36.2 \pm 14.9$ & $0.250 \pm 0.083$ & $35.1 \pm 18.8$ & $0.674 \pm 0.187$ \\
F2 free testosterone $(\mathrm{pg} / \mathrm{mL})$ & $52.4 \pm 20.8 *$ & $0.194 \pm 0.054$ & $55.5 \pm 31.1 *$ & $0.798 \pm 0.247$ \\
F1 dihydrotestosterone $(\mathrm{ng} / \mathrm{mL})$ & $0.519 \pm 0.222$ & $0.410 \pm 0.105$ & $1.39 \pm 0.87$ & $1.14 \pm 0.49$ \\
F2 dihydrotestosterone $(\mathrm{ng} / \mathrm{mL})$ & $0.578 \pm 0.245$ & $0.451 \pm 0.066$ & $1.17 \pm 0.47$ & $0.850 \pm 0.336$ \\
\hline
\end{tabular}

For all calculations, the predose concentration is subtracted from the determined concentration after dosing. The values are mean \pm SD. The means of F1 are calculated with the data of 13 women and the means of F2 are based on the data of 12 women

To convert total testosterone to nanomoles per liter, multiply by 3.467

AUC area under the curve, $C_{\max }$ maximum concentration, $T_{\max }$ time to maximum concentration, $T_{1 / 2}$ half-life

$* p<0.05$, value at $\mathrm{F} 2$ is significantly different from $\mathrm{F} 1$

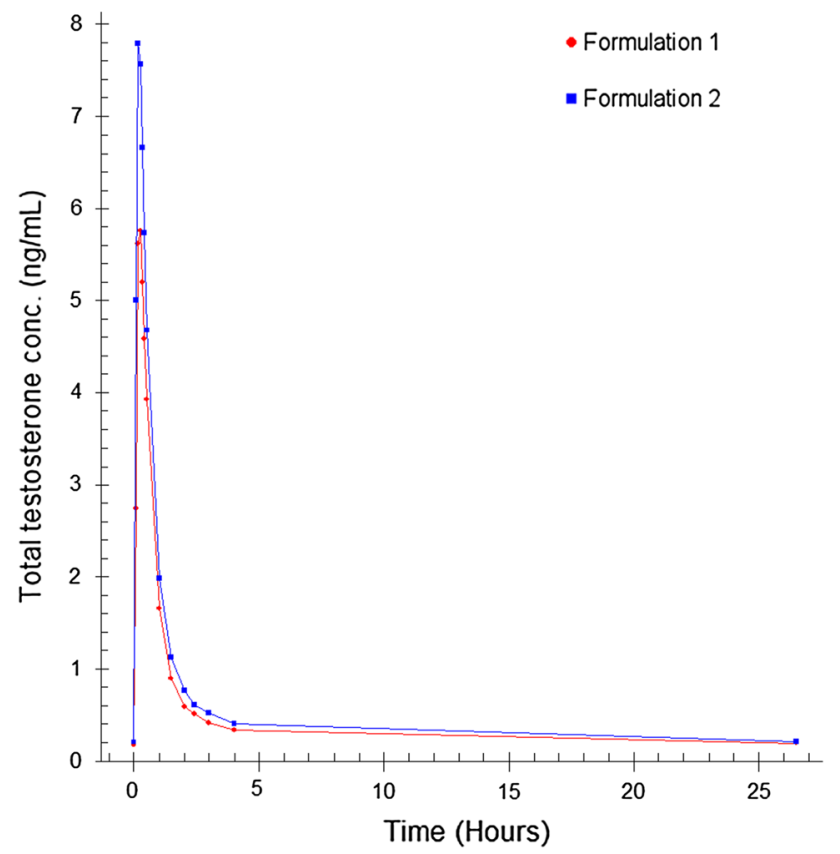

Fig. 1 Mean total testosterone plasma concentration-time profile

testosterone $(p=0.018)$ and not statistically significant for total testosterone ( $p=0.078$ ) compared with the F1 dosing. The pharmacokinetic parameters of total and free testosterone and dihydrotestosterone after the different modes of administration are summarized in Table 2.

The mean concentrations of testosterone, free testosterone, and dihydrotestosterone measured after sublingual administration of a single dose of testosterone $(0.50 \mathrm{mg})$ after F1 and F2 administration are shown in the Figs. 1, 2 and 3 .

\subsubsection{Buspirone and 1-(2-Pyrimidinyl)-Piperazine}

Pharmacokinetic results of the two administrations show that from both products, buspirone was absorbed with a

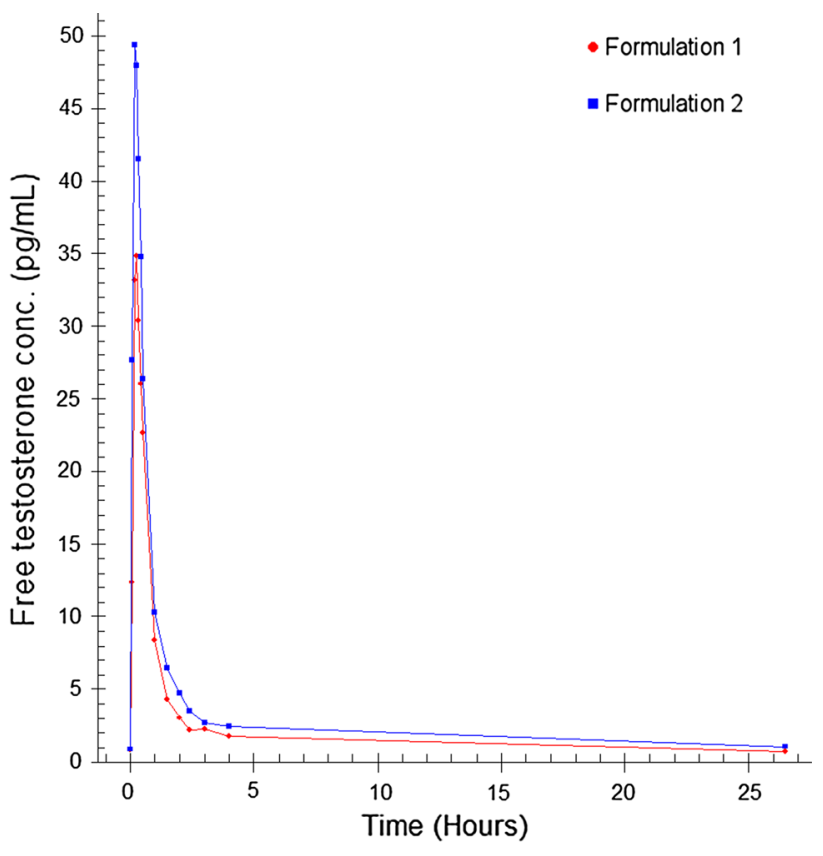

Fig. 2 Mean free testosterone plasma concentration-time profile

$T_{\max }$ between 3.69 and 3.95 hours and a half-life between 6.03 and 7.12 hours. Buspirone Tlag (median) was approximately 3 hours after F1 and approximately 3 hours and 20 minutes after F2 administration. Since for F1 the encapsulated tablet was taken after 150 minutes $(2.5 \mathrm{~h})$, the in vivo dissolution and absorption of buspirone took 30 minutes. The in vivo lag time for F2 was $200-$ $30=170$ minutes, which was well in line with in vitro observations of the tablet. 1-(2-pyrimidinyl)-piperazine reached the maximum concentration after approximately 4 hours (4.02-4.40 h) with a half-life between 4.84 and 4.86 hours. $C_{\max }$ and AUC were not significantly different between the F1 and F2 administration for buspirone as well as 1-(2-pyrimidinyl)-piperazine. 
The pharmacokinetic parameters of buspirone and its primary metabolite 1-(2-pyrimidinyl)-piperazine after the F1 and F2 modes of administration are summarized in Table 3.

The mean concentration-time profiles of buspirone and 1-(2-pyrimidinyl)-piperazine measured after oral administration of a single dose of buspirone $(10 \mathrm{mg})$ using the $\mathrm{F} 1$ and F2 modes of administration are shown in Figs. 4 and 5.

The two formulations were well tolerated.

\section{Discussion}

Our results demonstrate that sublingual administration of testosterone in both formulations was followed by a very quick and steep increase of total and free testosterone levels; with peak levels reached between 10 and 20 minutes, which is in line with our previous studies $[9,26]$.

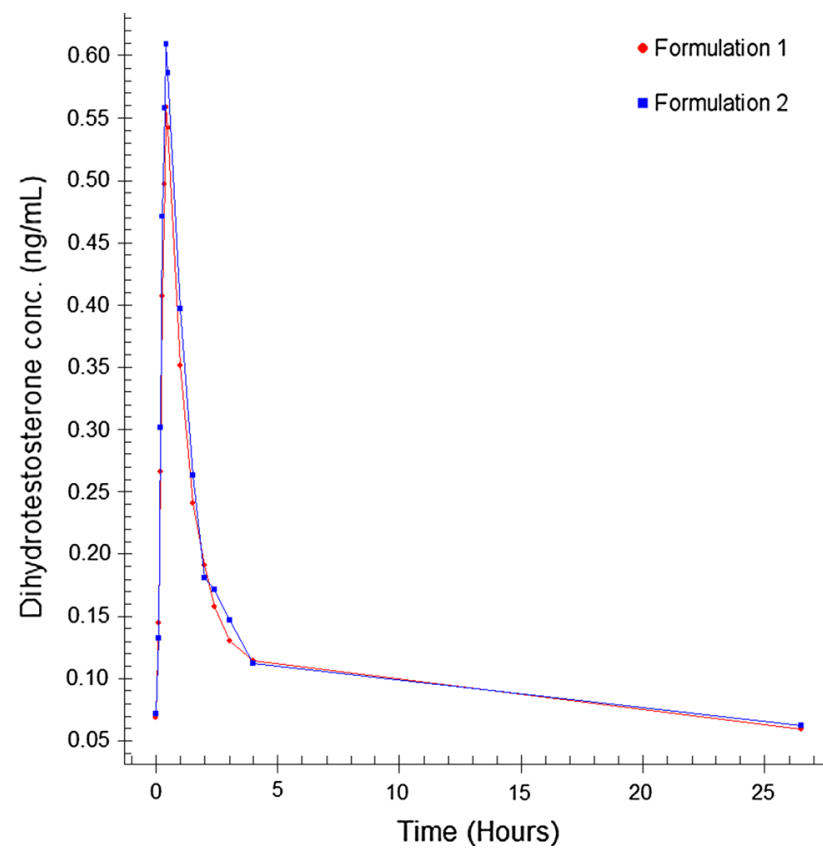

Fig. 3 Mean dihydrotestosterone plasma concentration-time profiles

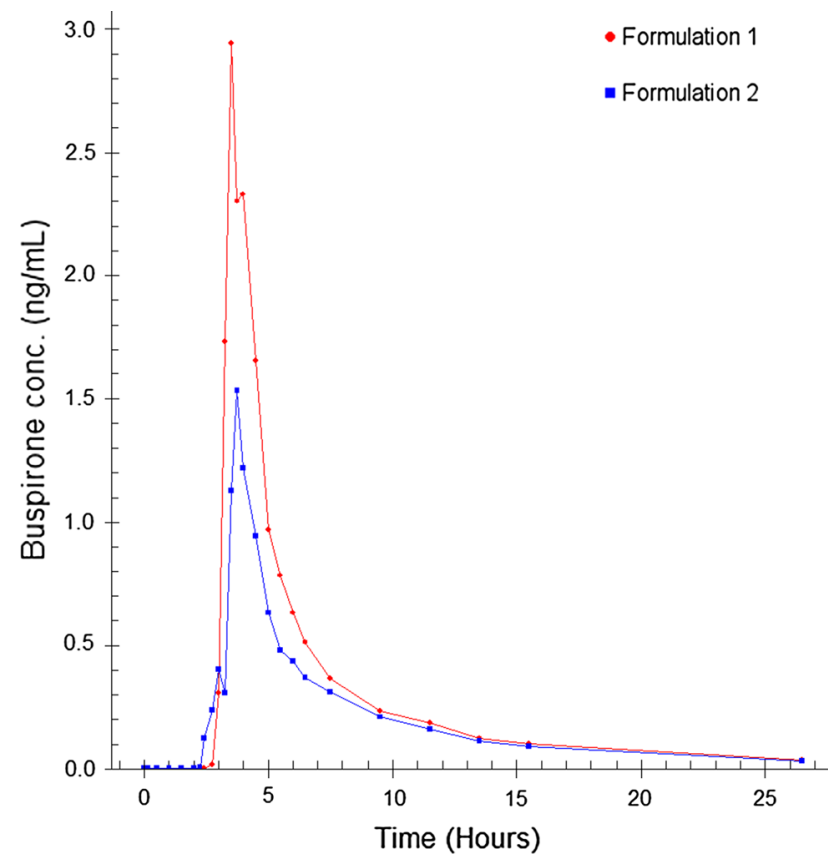

Fig. 4 Mean buspirone plasma concentration-time profile

Serum levels of total and free testosterone rapidly declined to reach baseline levels by approximately 2.5 hours.

The total testosterone $C_{\max }$ following administration of $0.50 \mathrm{mg}$ sublingual testosterone after the liquid dosing regimen showed consistency with the reported $C_{\max }$ of Tuiten et al. and van Rooij et al. [9, 26]; however, the $C_{\max }$ of total and free testosterone after administration of the tablet is higher. This is also reflected by the AUC for total and free testosterone after administration of the tablet compared with the liquid dosing, meaning very fast absorption from the solid polymeric matrix. Since there is no time delay or difference in absorption for the two formulations, the in vivo dissolution of testosterone from the tablet coating is not the rate-limiting step in the absorption process, which indicates that the driving force for dissolution in the saliva is high. It is surprising that the bioavailability of testosterone from the tablet is higher than from the liquid, since one would expect it to be the other way around, and certainly for an

Table 3 Pharmacokinetic parameters for buspirone and 1-(2-pyrimidinyl)-piperazine after either F1 or F2 administration

\begin{tabular}{|c|c|c|c|c|c|c|}
\hline Dosing & $\begin{array}{l}C_{\max }(\mathrm{ng} / \\
\mathrm{mL})\end{array}$ & $T_{\max }(\mathrm{h})$ & $\begin{array}{l}\mathrm{AUC}_{(0-1,590)} \\
(\mathrm{ng} * \mathrm{~h} / \mathrm{mL})\end{array}$ & $\begin{array}{l}\text { AUC extrapolated } \\
\left(\mathrm{ng}{ }^{*} \mathrm{~h} / \mathrm{mL}\right)\end{array}$ & Tlag (h) & $T_{1 / 2}(\mathrm{~h})$ \\
\hline F1 buspirone (ng/mL) & $3.95 \pm 4.38$ & $3.69 \pm 0.54$ & $7.63 \pm 8.07$ & $8.02 \pm 8.57$ & $2.96 \pm 0.14$ & $6.03 \pm 2.27$ \\
\hline F2 buspirone (ng/mL) & $2.16 \pm 2.55$ & $3.95 \pm 1.82$ & $5.14 \pm 5.08$ & $5.56 \pm 5.24$ & $3.33 \pm 0.82$ & $7.12 \pm 2.33$ \\
\hline $\begin{array}{l}\text { F1 1-(2-pyrimidinyl)-piperazine } \\
\text { (ng/mL) }\end{array}$ & $4.35 \pm 1.65$ & $4.02 \pm 0.68$ & $25.4 \pm 14.60$ & $27.4 \pm 17.8$ & $3.27 \pm 0.33$ & $4.84 \pm 2.11$ \\
\hline $\begin{array}{l}\text { F2 1-(2-pyrimidinyl)-piperazine } \\
\text { (ng/mL) }\end{array}$ & $3.99 \pm 1.71$ & $4.40 \pm 2.27$ & $21.6 \pm 6.7$ & $22.7 \pm 7.4$ & $3.58 \pm 1.32$ & $4.86 \pm 1.66$ \\
\hline
\end{tabular}

The values are mean \pm SD. The means of F1 are calculated with the data of 13 women and the means of F2 are based on the data of 12 women $A U C$ area under the curve, $C_{\max }$ maximum concentration, Tlag absorption lag time, $T_{\max }$ time to maximum concentration, $T_{1 / 2}$ half-life 


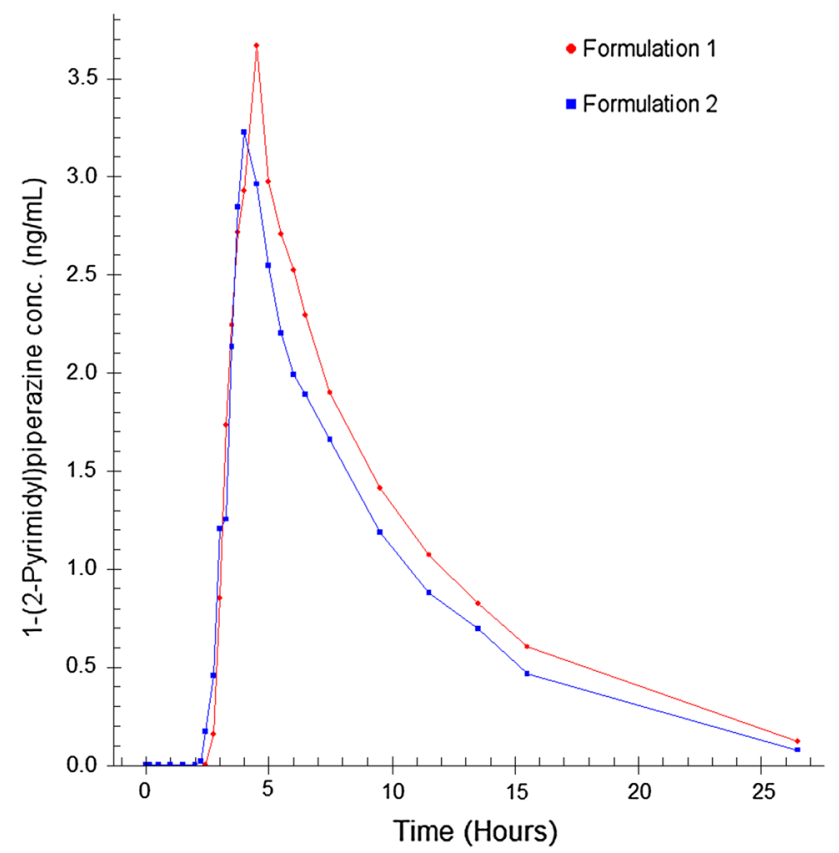

Fig. 5 Mean 1-(2-pyrimidinyl)-piperazine plasma concentrationtime profile

intrinsically insoluble compound such as testosterone. On the other hand, it should be taken into account that a small amount of the liquid testosterone $(0.5 \mathrm{ml})$ may leak away to the esophagus and stomach which could explain the lower bioavailability of this dosage form compared with the combination tablet. In a previous study of van Rooij et al., three different doses of the liquid testosterone were investigated $(0.25,0.50$, and $0.75 \mathrm{mg})$ and it was observed that the lowest testosterone dose $(0.25 \mathrm{mg})$ had the highest bioavailability [26]. In that study, the $0.50 \mathrm{mg}$ of sublingual testosterone solution had a relative availability to the lowest dose of $69 \%$. The AUC of the lowest dose was dose corrected equivalent to a $0.3 \mathrm{mg}$ single pulmonal testosterone dose described by Davison and colleagues [27]. Due to the properties of testosterone, the low dose, and the large surface area of the lungs, it was anticipated that this was a near $100 \%$ bioavailability, resulting in an approximate $70 \%$ bioavailability for the $0.5 \mathrm{mg}$ liquid sublingual dose. And since the new combination tablet with the coating of testosterone has both a higher $C_{\max }$ and AUC, we assume that the absolute bioavailability of this tablet is above 70 and probably close to $80 \%$.

The metabolite dihydrotestosterone peak levels were reached within 30 minutes and levels returned to baseline levels within 4 hours, which is also consistent with our previous pharmacokinetic study [26].

Due to the high first-pass effect, the variability between the subjects for the buspirone levels was as expected very high. The Tlag time and the $T_{\max }$ for both buspirone and its metabolite 1-(2-pyrimidinyl)-piperazine were comparable for both formulations. This indicates that the in vivo rupture time of the tablet is within the set specification of 120-240 minutes (average $150 \mathrm{~min}$ ).

Although the $C_{\max }$ for buspirone was not significantly different between the two formulations, the average $C_{\max }$ was somewhat lower for the combination tablet (F2) compared with the encapsulated tablet (F1) taken after 150 minutes. The encapsulated gelatin capsule of F1 is probably absorbed in the stomach, while the combination tablet is absorbed at a more distal location in the gastrointestinal tract (in the small intestines). Since the combination tablet will release its drug load after a 150-minute longer travel through the gastrointestinal tract, this could have influenced the $C_{\max }$ for buspirone. However, based on the AUC of the main first-pass metabolite of buspirone, there does not seem to be a significant incomplete absorption of the buspirone, but rather a more extensive first-pass effect with the tablet that resides longer and further in the gastrointestinal tract.

\section{Conclusion}

In conclusion, there was adequate absorption of both testosterone and buspirone and an adequate time delay for the release of buspirone after administration of the combination tablet, which is a well tolerated, convenient and suitable formulation for Lybridos administration in a daily practical setting. All subsequent clinical studies, including dose-finding studies, will be done with this innovative tablet formulation.

Acknowledgments Funding for this study was provided by Emotional Brain BV. The authors wish to thank A.C. Eissens for his assistance in the development of the combination tablet. We acknowledge the personnel of QPS Netherlands for their excellent care of the subjects.

Conflict of interest Four authors (KvR, JB, SP, HK) are employees of Emotional Brain (EB) and AT is CEO of EB. LdL is consultant to EB and Director at Exelion Bio-Pharmaceutical Consultancy BV. HF declares that his employer has a royalty agreement with EB. KvR, LdL, JB, SP, HK, BO, and AT own shares and or stock options in EB.

Author Contributions $\mathrm{KvR}, \mathrm{LdL}, \mathrm{HF}, \mathrm{JB}, \mathrm{SP}, \mathrm{HK}, \mathrm{BO}$, and AT wrote the manuscript; KvR, LdL, JB, and SP designed and executed the research; KvR, LdL, and JB analyzed the data; LdL and HF developed the tablet and contributed analytical tools.

Open Access This article is distributed under the terms of the Creative Commons Attribution Noncommercial License which permits any noncommercial use, distribution, and reproduction in any medium, provided the original author(s) and the source are credited.

\section{References}

1. Laumann EO, Paik A, Rosen RC. Sexual dysfunction in the United States: prevalence and predictors. JAMA. 1999;281:537-44. 
2. Fugl-Meyer KS. Sexual disabilities and sexual problems. In: Sex in Sweden. Stockholm: National Institute of Public Health; 2000. pp. 199-216.

3. Shifren JL, Monz BU, Russo PA, Segreti A, Johannes CB. Sexual problems and distress in United States women: prevalence and correlates. Obstet Gynecol. 2008;112:970-8.

4. Davison SL, Bell RJ, LaChina M, Holden SL, Davis SR. The relationship between self-reported sexual satisfaction and general well-being in women. J Sex Med. 2009;6:2690-7.

5. American Psychiatric Association. Diagnostic and statistical manual of mental disorders. 4th edn. Washington, DC; 2000.

6. American Psychiatric Association. Diagnostic and statistical manual of mental disorders. 5th edn. Arlington, VA: American Psychiatric Publishing; 2013.

7. Poels S, Bloemers J, van Rooij K, Goldstein I, Gerritsen J, van Ham D, van Mameren F, Chivers M, Everaerd W, Koppeschaar $\mathrm{H}$, Olivier B, Tuiten A. Toward personalized sexual medicine (part 2): testosterone combined with a PDE5 inhibitor increases sexual satisfaction in women with HSDD and FSAD, and a low sensitive system for sexual cues. J Sex Med. 2013;10:810-23.

8. van Rooij K, Poels S, Bloemers J, Goldstein I, Gerritsen J, van Ham D, van Mameren F, Chivers M, Everaerd W, Koppeschaar $\mathrm{H}$, Olivier B, Tuiten A. Toward personalized sexual medicine (part 3): testosterone combined with a Serotonin1A receptor agonist increases sexual satisfaction in women with HSDD and FSAD, and dysfunctional activation of sexual inhibitory mechanisms. J Sex Med. 2013;10:824-37.

9. Tuiten A, Van Honk J, Koppeschaar H, Bernaards C, Thijssen J, Verbaten R. Time course of effects of testosterone administration on sexual arousal in women. Arch Gen Psychiatry. 2000; 57:149-53 discussion 155-156.

10. van der Made F, Bloemers J, Yassem WE, Kleiverda G, Everaerd W, van Ham D, et al. The influence of testosterone combined with a PDE5-inhibitor on cognitive, affective, and physiological sexual functioning in women suffering from sexual dysfunction. J Sex Med. 2009;6(3):777-90.

11. Postma A, Meyer G, Tuiten A, van Honk J, Kessels RP, Thijssen J. Effects of testosterone administration on selective aspects of object-location memory in healthy young women. Psychoneuroendocrinology. 2000;25:563-75.

12. Aleman A, Bronk E, Kessels RP, Koppeschaar HP, van Honk J. A single administration of testosterone improves visuospatial ability in young women. Psychoneuroendocrinology. 2004;29:612-7.

13. Schutter DJ, van Honk J. Decoupling of midfrontal delta-beta oscillations after testosterone administration. Int J Psychophysiol. 2004;53:71-3.

14. van Honk J, Schutter DJ, Hermans EJ, Putman P, Tuiten A, Koppeschaar H. Testosterone shifts the balance between sensitivity for punishment and reward in healthy young women. Psychoneuroendocrinology. 2004;29:937-43.
15. van Honk J, Peper JS, Schutter DJ. Testosterone reduces unconscious fear but not consciously experienced anxiety: implications for the disorders of fear and anxiety. Biol Psychiatry. 2005;58:218-25.

16. van Honk J, Schutter DJ. Testosterone reduces conscious detection of signals serving social correction: implications for antisocial behavior. Psychol Sci. 2007;18:663-7.

17. van Honk J, Tuiten A, Hermans E, Putman P, Koppeschaar H, Thijssen J, Verbaten R, van Doornen L. A single administration of testosterone induces cardiac accelerative responses to angry faces in healthy young women. Behav Neurosci. 2001;115:238-42.

18. Hermans EJ, Putman P, van Honk J. Testosterone administration reduces empathetic behavior: a facial mimicry study. Psychoneuroendocrinology. 2006;31:859-66.

19. Hermans EJ, Putman P, Baas JM, Gecks NM, Kenemans JL, van Honk J. Exogenous testosterone attenuates the integrated central stress response in healthy young women. Psychoneuroendocrinology. 2007;32:1052-61.

20. Hermans EJ, Ramsey NF, van Honk J. Exogenous testosterone enhances responsiveness to social threat in the neural circuitry of social aggression in humans. Biol Psychiatry. 2008;63:263-70.

21. Bos PA, Terburg D, van Honk J. Testosterone decreases trust in socially naive humans. Proc Natl Acad Sci USA. 2010;107:9991-5.

22. Eisenegger C, Naef M, Snozzi R, Heinrichs M, Fehr E. Prejudice and truth about the effect of testosterone on human bargaining behaviour. Nature. 2010;463:356-9.

23. Bos PA, van Honk J, Ramsey NF, Stein DJ, Hermans EJ. Testosterone administration in women increases amygdala responses to fearful and happy faces. Psychoneuroendocrinology. 2013;38:808-17.

24. Labrie F, Belanger A, Belanger P, Berube R, Martel C, Cusan L, Gomez J, Candas B, Castiel I, Chaussade V, Deloche C, Leclaire J. Androgen glucuronides, instead of testosterone, as the new markers of androgenic activity in women. J Steroid Biochem Mol Biol. 2006;99:182-8.

25. Miller KK, Rosner W, Lee H, Hier J, Sesmilo G, Schoenfeld D, Neubauer G, Klibanski A. Measurement of free testosterone in normal women and women with androgen deficiency: comparison of methods. J Clin Endocrinol Metab. 2004;89:525-33.

26. van Rooij K, Bloemers J, de Leede L, Goldstein I, Lentjes E, Koppeschaar H, Olivier B, Tuiten A. Pharmacokinetics of three doses of sublingual testosterone in healthy premenopausal women. Psychoneuroendocrinology. 2012;37:773-81.

27. Davison S, Thipphawong J, Blanchard J, Liu K, Morishige R, Gonda I, Okikawa J, Adams J, Evans A, Otulana B, Davis S. Pharmacokinetics and acute safety of inhaled testosterone in postmenopausal women. J Clin Pharmacol. 2005;45:177-84. 